\title{
Analysis of peripherally inserted central catheter-related complications: a retrospective cohort study of 2,974 children with blood diseases in a single center of China
}

\author{
Li-Xian Chang, Yu-Wen Chen, Meng-Chuan Wang, Su-Yu Zhao, Min Wang, Yang Tian, Li Tang, \\ Jun-Xia Wang, Miao-Miao Yang, Xiao-Fan Zhu, Hui-Min Zhang
}

State Key Laboratory of Experimental Hematology, National Clinical Research Center for Blood Diseases, Institute of Hematology \& Blood Diseases Hospital, Chinese Academy of Medical Sciences \& Peking Union Medical College, Tianjin, China

Contributions: (I) Conception and design: LX Chang, XF Zhu, HM Zhang; (II) Administrative support: None; (III) Provision of study materials or patients: YW Chen, MC Wang, SY Zhao, M Wang; (IV) Collection and assembly of data: L Tang, JX Wang, MM Yang; (V) Data analysis and interpretation: All authors; (VI) Manuscript writing: All authors; (VII) Final approval of manuscript: All authors.

Correspondence to: Xiao-Fan Zhu or Hui-Min Zhang. State Key Laboratory of Experimental Hematology, National Clinical Research Center for Blood Diseases, Institute of Hematology \& Blood Diseases Hospital, Chinese Academy of Medical Sciences \& Peking Union Medical College, 288 Nanjing Road, Tianjin 300020, China. Email: xfzhu@ihcams.ac.cn or zhanghuimin@ihcams.ac.cn.

\begin{abstract}
Backgrounda Although the peripherally inserted central catheter (PICC) has been widely utilized, there is still a lack of large sample size-based relevant risk factor investigation for the children with blood diseases in a single center of China.
\end{abstract}

Methods: We performed a retrospective cohort study through including a total of 2,974 cases aged 0-18 years with blood diseases and PICC insertion. Success rates of different PICC operation techniques were compared. Targeting the common PICC-related complications, we performed the univariate and multivariate logistic regression analyses. Then, based on the screened risk factors, the prediction modeling analysis of binary logistic regression was conducted.

Results: The "B-ultrasound plus Seldinger technology" showed a higher success rate of PICC placement than the "non-assistive blind insertion". The catheter type was closely linked to the occurrence of catheter occlusion. The age, insertion site, and catheter type might be the risk factors of phlebitis, while the insertion site, operation season, and catheter type might be associated with catheter fracture. Furthermore, based on these risk factors, we established the nomogram prediction models of phlebitis, rash occurrence, and catheter fracture, respectively, which shows a good predictive ability and a moderate level of predictive accuracy.

Conclusions: Our findings first shed new light on the preoperative estimation of the risk factors of PICCrelated complications for the children with blood diseases in China.

Keywordsः Peripherally inserted central catheter (PICC); risk; blood disease; complication; children

Submitted Sep 03, 2020. Accepted for publication Dec 24, 2020.

doi: 10.21037/apm-20-1771

View this article at: http://dx.doi.org/10.21037/apm-20-1771

\section{Introduction}

The peripherally inserted central catheter (PICC) with safe venous entry has been widely utilized for patients with a variety of severe diseases, especially tumors (1-3). PICC can significantly reduce the number of venipunctures in patients with chemotherapy or long-term treatment, and the chemotherapy drug-induced blood vessel damage $(1,4)$.

Since PICC catheterization was introduced into China in the late 1990s, PICC has been extensively used in tumor chemotherapy, nutritional pathway establishment of premature infants, and tumor chemotherapy of children $(5,6)$. PICC helps hospitalized infants or children with pain 
relief during treatment. However, a series of PICC-related complications, such as infection, phlebitis, rash, catheter occlusion, or fracture after PICC implantation still occurred (6-9). It is meaningful to systematically analyze the PICCrelated clinical complications, based on a large sample size.

In this study, we performed a retrospective cohort study for the comparison of different PICC insertion technologies, and the risk factor investigation of common PICC-related non-infectious complications (rash, phlebitis, rash occurrence, and catheter fracture), by including nearly 3,000 Chinese children with hematologic diseases, collected by our center over fourteen years. Several risk factors, including gender, age, insertion site, operation season, and catheter type, were concerned. We present the following article in accordance with the MDAR checklist (available at http://dx.doi.org/10.21037/apm-20-1771).

\section{Methods}

\section{Patients}

Between March 2004 and December 2018, a total of 2,974 patients aged $0-18$ years old with hematological diseases who underwent PICC placement were enrolled in our retrospective study. The study was conducted in accordance with the Declaration of Helsinki (as revised in 2013). Our study has been were reviewed and approved by the clinical research ethics committee of Blood Diseases Hospital \& Institute of Hematology, Chinese Academy of Medical Sciences [HG2020007-EC-1]. Due to the low risk of retrospective project, consent was not required. We extracted the basic information, such as gender, age, disease type, therapy, surgical method, insertion site, operation season, catheter type, PICC-related complications, and analyzed the distribution feature of the age, gender, disease type, and therapy.

\section{PICC operation}

Using the sterile technique, the catheter was inserted at the bedside or operating room by qualified PICC nurses. Before placing the tube, the puncture arm must be thoroughly cleaned with chlorhexidine disinfectant. There are four types of PICC techniques, namely the "non-assistive blind insertion", "only B-ultrasound", "only Seldinger", and "B-ultrasound plus Seldinger". The success rates of these technologies were analyzed. Two puncture positions of the catheter, including "under the elbow" and "above the elbow", were used in our center. There were three main types of catheter, namely Groshong ${ }^{\circledR}$ NXT ClearVue ${ }^{\mathrm{TM}}$ Catheter 4F (4F), Groshong ${ }^{\circledR}$ Catheter 3F (3F), and Power catheter (power). We selected the catheter type based on the principle that the ratio of the catheter to vessel diameter (A/B) was less than $45 \%$ (Figure S1).

\section{Complication definition}

PICC-related complications were monitored and treated by the clinicians and nurses in our center. The complications, such as infection, catheter occlusion, catheter fracture, and phlebitis, were defined according to the guidance of "Infusion Nursing Standards of Practice" (10). The incidence curve of common PICC-related complications was made.

\section{Statistical analysis}

Using the SPSS software (IBM SPSS statistics 20), we performed the chi-square test to analyze the difference in the success rate of different surgical methods. $\chi^{2}$ and $\mathrm{P}$ values were provided. Bonferroni-adjusted $\mathrm{P}$ values were used for the comparison of the two groups.

Besides, we utilized the "rms" $\mathrm{R}$ package to perform the univariate and multivariate logistic regression analyses to analyze the potential risk factors of the common complications, respectively. The sample size, odds ratio (OR), 95\% confidence interval (CI), and unadjusted $\mathrm{P}$ value in the univariate logistic regression analysis were shown in a table. The result of multivariate logistic regression analysis was visualized as a forest plot with adjusted $\mathrm{P}$ value, OR with $95 \%$ CI, using "plot ()" $\mathrm{R}$ function. P values $<0.05$ were considered statistically significant. Positive results in forest plot were marked with a red box.

Then, we performed the modeling analysis of binary logistic regression for the phlebitis, rash occurrence, and catheter fracture, respectively. After data sorting, only the cases with full clinical information $(n=2,939)$ were enrolled. Using R functions of "sample ()", a total of 2,057 cases was randomly selected as training cohort, and 882 cases were used as test cohort. Based on the R functions of "lrm ()", "nomogram ()", and "plot ()", we obtained the nomogram and followed the forest plot in the training cohort. The "calibrate ()" function of the "ggstatspot" R package was also used to obtain the calibration curve for the assessment of the difference between the predicted and true value. Finally, we performed the receiver operating characteristic 
Table 1 Distribution feature of enrolled patients with PICC

\begin{tabular}{lccc}
\hline Distribution factor & Group & Number & $\%$ \\
\hline Age & Mean age & 6.2 & $0.1-18^{*}$ \\
Gender & Male & 1,797 & $60.4 \%$ \\
Demale & 1,177 & $39.6 \%$ \\
& ALL & 2,259 & $76 \%$ \\
& AML & 349 & $11.7 \%$ \\
& APL & 64 & $2.2 \%$ \\
& HAL & 2 & $0.07 \%$ \\
& Lymphoma & 36 & $1.2 \%$ \\
& MDS & 4 & $0.1 \%$ \\
HPS & 1 & $0.03 \%$ \\
JMML & 2 & $0.06 \%$ \\
& SAA & 255 & $8.5 \%$ \\
HA & 1 & $0.03 \%$ \\
\hline
\end{tabular}

*, age range; ALL, acute lymphoblastic leukemia; AML, acute myeloblastic leukemia; APL, acute promyelocytic leukemia; HAL, acute heterozygotic leukemia; MDS, myelodysplastic syndrome; HPS, haemophilic cell syndrome; JMML, juvenile chronic granular mononuclear leukemia; SAA, sever aplastic anemia; HA, hemolytic anemia.

(ROC) analysis in both training and test cohorts, using the "pROC" R package. And the value of area under curve (AUC) was shown in the ROC curve, through the setting of "print.auc=TRUE" in the "plot.roc ()" function. The software of R language (version R-3.6.1) was utilized.

\section{Results}

\section{Distribution feature of included patients with PICC}

A total of 2,974 children blood disease patients with PICC was enrolled in our study. As shown in Table 1, the mean age was 6.2 years old (from 0.1 to 18 years), and $60.4 \%$ $(\mathrm{n}=1,797)$ of patients were male. The main type is acute lymphoblastic leukemia (ALL, 76\%, $\mathrm{n}=2,259$ ). In addition, the patients of ALL, acute promyelocytic leukemia (APL), acute myeloblastic leukemia (AML), acute heterozygotic leukemia (HAL), myelodysplastic syndrome (MDS), haemophilic cell syndrome (HPS), and juvenile chronic granular mononuclear leukemia (JMML) underwent the chemotherapy, while the patients of sever aplastic anemia (SAA) and hemolytic anemia (HA) received the immunosuppressive therapy.

\section{Success rate difference of PICC operation techniques}

Based on the PICC operation technique, we obtained four groups, namely "non-assistive blind insertion" $(\mathrm{n}=550)$, "only B-ultrasound" ( $\mathrm{n}=48)$, "only Seldinger" $(\mathrm{n}=1,067)$, and "B-ultrasound plus Seldinger" $(\mathrm{n}=1,309)$. The success rate of these four groups was analyzed. As shown in Table 2, we observed a significant statistical difference among these techniques $(\mathrm{P}<0.01)$. The success rate of PICC insertion in the "B-ultrasound plus Seldinger" group and "only Seldinger group" are statistically higher than that in the "none-assistive blind insertion" group (Table 2).

\section{Complication status analysis data}

There were four types of common complications, including the rash (453 cases, 15.2\%), catheter occlusion (433 cases, $14.6 \%)$, mechanical phlebitis (282 cases, $9.5 \%$ ), and internal/external catheter fracture (164 cases, $5.5 \%)$, and several rare complications, including the total catheter detachment (34 cases, $1.1 \%$ ), catheter-related bloodstream infection ( 9 cases, $0.3 \%$ ), catheter rupture (intravascular 2 cases, $0.06 \%$; extravascular 9 cases, $0.3 \%$ ). Therefore, we focused on the assessment of the risk factors of the above four common complications. The annual incidence trends of common complications were indicated in Figure 1. We observed a clear downward trend for the complications of phlebitis and external catheter fracture, and a peak for the complications of catheter occlusion in 2015 or rash in 2016 (Figure 1).

\section{Logistic regression analysis data}

Next, we first utilized the univariate and multivariate logistic regression analyses to determine the potential risk factors of the rash complication, respectively. The factors of gender (male, female) and age (1-3, 4-6, 7-10, and 11-18), insertion site (above/under the elbow), catheter type (3F, 4F, and power), operation season (spring, summer, autumn, and winter) were considered. The univariate logistic regression analysis results of rash (Table S1) showed a decreased risk of rash in the groups of "female" $(\mathrm{OR}=0.678, \mathrm{P}<0.001)$, "4-6" (OR =0.714, $\mathrm{P}=0.008)$, "7-10" $(\mathrm{OR}=0.55, \mathrm{P}<0.001)$, "11-18" (OR =0.536, $\mathrm{P}<0.001)$, "under the elbow" (OR $=0.552, \mathrm{P}<0.001)$, "autumn" $(\mathrm{OR}=0.682, \mathrm{P}=0.008)$, "winter" $(\mathrm{OR}=0.66, \mathrm{P}=0.005)$, when comparing with the 
Table 2 Comparison of success rate of different PICC operation techniques

\begin{tabular}{lcccc}
\hline Group & Title number & Success & Failure & $\chi^{2}$ \\
\hline None-assistive blind insertion & 550 & 531 & $19^{\mathrm{a}, \mathrm{b}}$ & 33.613 \\
Only B-ultrasound & 48 & 47 & 1 & - \\
Only Seldinger & 1,067 & 1,056 & $11^{\mathrm{a}}$ & - \\
B-ultrasound plus Seldinger & 1,309 & 1,305 & $4^{\mathrm{b}}$ & - \\
Total & 2,974 & 2,939 & 35 & - \\
\hline
\end{tabular}

a,b , statistically significant difference between "only Seldinger" group and "B-ultrasound plus Seldinger" group.

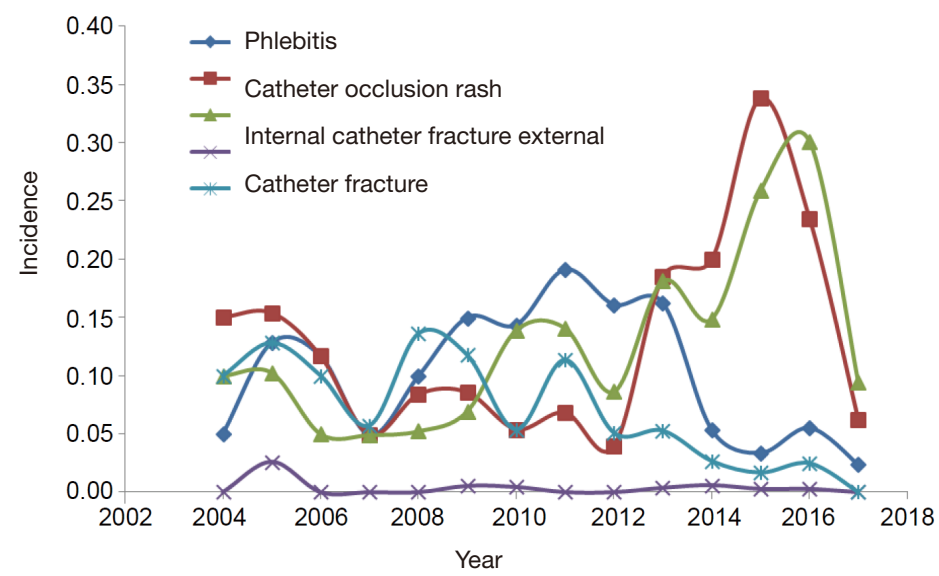

Figure 1 Incidence curve of common PICC-related complications.

corresponding control groups of "male", "0-3", "above the elbow", and "spring", respectively. In terms of the catheter type, there is a higher risk of rash in the "power" group (Table $\mathrm{S} 1, \mathrm{OR}=1.903, \mathrm{P}<0.001$ ), but a lower risk in the "4F" group $(\mathrm{OR}=0.465, \mathrm{P}<0.001)$, than that in the "3F" group. Furthermore, we performed the multivariate logistic regression analysis and showed the result as a forest plot in Figure S2. We observed similar results for the factors of gender, age, operation season (all $\mathrm{OR}<1, \mathrm{P}<0.05$ ), and catheter type $(\mathrm{OR}=0.713, \mathrm{P}=0.027$ for " $4 \mathrm{~F}$ "; $\mathrm{OR}=3.018$, $\mathrm{P}<0.001$ for "power"), but not the insertion site $(\mathrm{P}=0.132$, Figure S2). These suggested that the gender, age, insertion site, catheter type, and operation season might be the risk factor of PICC-related rash. The male PICC Children (" $0-3$ " years) hospitalized in the spring and summer with the catheter type of "power" are more likely to suffer from the rash complication.

Using the same analytical approach, we performed the univariate and multivariate logistic regression analyses for the complications of catheter occlusion, phlebitis, and catheter fracture, respectively. We obtained the potential risk factors for each complication. Briefly, with regards to catheter occlusion, we only obtained one risk factor, namely the catheter type (Table S2 and Figure S3). Compared with the PICC cases with " $3 \mathrm{~F}$ " catheter type, there is an increased risk of catheter occlusion in the "power" group (Table S2, OR =4.982, and Figure S3, OR =5.861, $\mathrm{P}<0.001$ ), but a reduced risk in " $4 \mathrm{~F}$ " group (Table $\mathrm{S} 2, \mathrm{OR}=0.404$, and Figure $\mathrm{S} 3, \mathrm{OR}=0.475, \mathrm{P}<0.001)$. In addition, the age, insertion site, and catheter type might be the risk factors of phlebitis (Table S3 and Figure S4), while the insertion site, operation season, and catheter type might be the risk factors of catheter fracture (Table S4 and Figure S5).

\section{Modeling analysis data of risk factors}

Based on the obtained risk factors, we performed the modeling analysis of binary logistic regression for phlebitis, respectively. The data was visualized by a nomogram and forest plot. As shown in Figure $2 A$, we combined three factors 


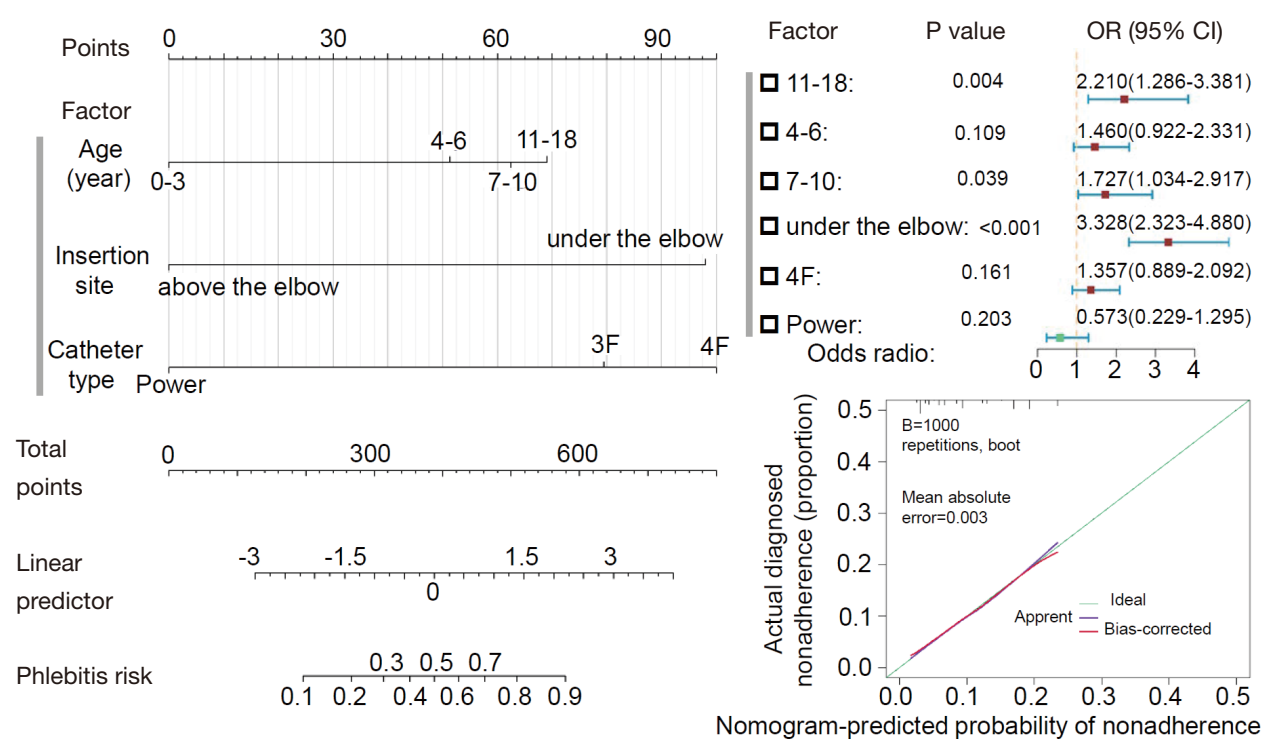

Figure 2 Modeling analysis based on the risk factors of phlebitis. (A) Nomogram; (B) Forest plot; (C) Calibration curve.

(age, insertion site, catheter type) to establish a prediction model of the nomogram for the assessment of phlebitis risk. Based on the total point of each PICC case, the rate of phlebitis risk can be predicted. Figure $2 B$ showed the corresponding forest plot. The predicted calibration curves (apparent and bias corrected) are closer to the ideal standard curve (Figure $2 C$ ), suggesting a better predictive ability of the nomogram. Furthermore, we observed a moderate level of predictive accuracy in both training (Figure $3 \mathrm{~A}, \mathrm{AUC}=0.704$ ) and test (Figure 3B, AUC $=0.714$ ) cohorts.

Based on the same modeling strategy, we provided the risk prediction models of rash occurrence (Figures S6,S7) and catheter fracture (Figures S8,S9) for the patients with PICC insertion. The modeling analysis of catheter occlusion was not conducted, due to the identification of only one risk factor, as stated above. There was an agreement of nomogram prediction with actual observation in the predicted calibration curves (Figure S6C and Figure S8C). Also, we detected a moderate level of predictive accuracy for the risk of rash in the test cohort (Figure S7B, AUC $=0.724$ ), but a slightly low level of predictive accuracy in the training cohort (Figure S7A, $\mathrm{AUC}=0.669$ ). There was also a moderate level of predictive accuracy for the risk of catheter fracture in both the training (Figure S9A, AUC $=0.717$ ) and test (Figure S9B, AUC $=0.728$ ) cohorts.

\section{Discussion}

In this study, we summarized the information on the PICC placement methods of all 2,974 cases ( $<18$ years) to analyze the difference in success rate. With the development of detection technology and clinical practice, the Seldinger and ultrasound techniques can be applied for the guiding of PICC placement (11-13). In our center, the most used PICC operation technique is "B-ultrasound plus Seldinger", followed by "only Selinger" and "none-assistive blind insertion". The Seldinger technique with or without B-ultrasound imaging shows a higher success rate than the outdated blind insertion. Even though we did not obtain the statistical difference of success rate between "B-ultrasound plus Seldinger" and "only Seldinger" groups, the success rate of the "B-ultrasound plus Seldinger" technique (99.7\%) is higher than that of "only Seldinger" (98.9\%). Thus, Seldinger technology with B-ultrasound imaging applies to pediatric patients with blood diseases.

We analyzed the potential links of several factors (gender, age, insertion site, catheter type, and operation season) and the presence of common PICC-related complications (rash, phlebitis, rash occurrence, and catheter fracture). In terms of gender, we only observed the potential link between females and the low risk of rash. For the age factor, the patients aged more than three years old tend to suffer from the occurrence of phlebitis but exhibit a lower risk of rash, compared with the patients ( $<3$ years old). Besides, we found that the patients with the PICC treatment in winter and autumn have a low risk of rash and catheter fracture. The possible reason is that spring is the season prone to allergic diseases, and male children aged $1-3$ years have 

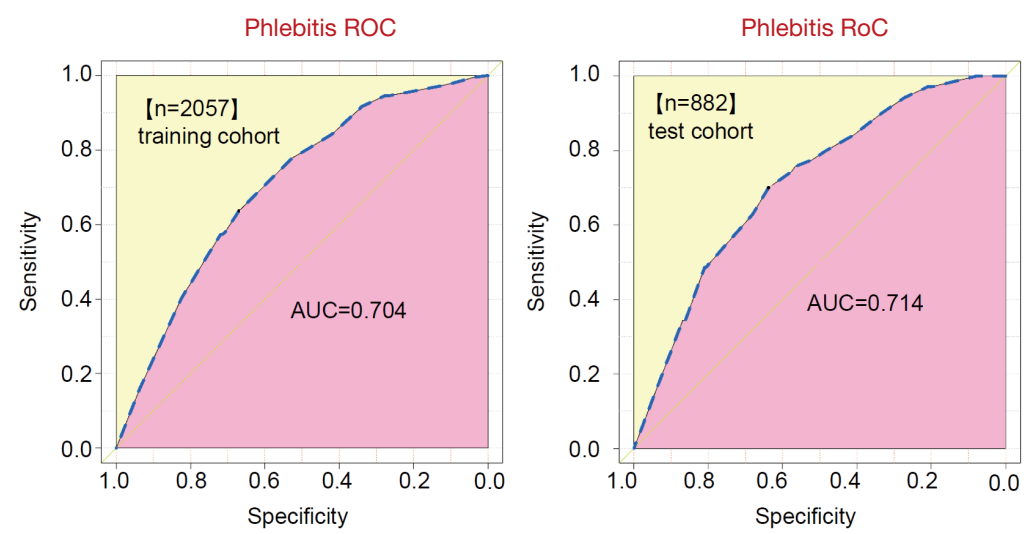

Figure 3 ROC data of phlebitis. (A) Training cohort; (B) test cohort.

high activity and sweat easily.

Differ PICC type was reported with the incidences of postinsertion complications (14). In our center, there are two types of catheter materials, namely silicone material ( $3 \mathrm{~F}$ and $4 \mathrm{~F}$ ) and polyurethane material (power). For this cohort, the most used type is " $4 \mathrm{~F}$ ", followed by " $3 \mathrm{~F}$ " and "Power". When compared to the "3F" group, there is a lower risk of rash, catheter occlusion, and catheter fracture in the "4F" group. Also, the cases with the "power" catheter showed a higher risk of rash and catheter occlusion, but a lower risk of phlebitis and catheter fracture, than that with the " $3 \mathrm{~F}$ " catheter. The catheter materials may contribute to the difference (15). The utilization of "power" catheter type might contribute to the peaks for the incidence of catheter occlusion in 2015 or rash in 2016 (Figure 1). Appropriately increasing the number of flushing is useful to reduce the occurrence of catheter occlusion for child patients who carried the "power" catheter. Besides, there is a higher risk of phlebitis and catheter fracture in the "under the elbow" group than that in the "above the elbow" group. To avoid placing catheters in areas of flexion is very important to reduce phlebitis. After 2011, the clear downward trend for the incidence of phlebitis and external catheter fracture (Figure 1) might be caused by the utilization of the insertion site (above the elbow) in our center.

Based on the above findings, we established a prediction nomogram model of phlebitis, rash, and catheter fracture, respectively. Using the nomogram, we can obtain the scores of each risk factor for one patient. Then, the sum of these scores leads to the "Total points", and the corresponding risk incidence of PICC-related complications.

PICC-associated complications include non-infectious and infectious categories (16-18). Infectious complications include infectious phlebitis, insertion site infection, catheter bacterial colonization, and catheter-related bloodstream infection (16). In contrast, non-infectious complications mainly include mechanical phlebitis, accidental catheter detachment, ectopic location, occlusion, damage, drainage, thrombosis, bleeding, nerve, or tendon injury $(17,18)$. The overall incidence of complications associated with PICC catheters was $25-50 \%$ or $4.6-11 / 1,000$ catheter days $(19,20)$. Our criteria for catheter-related bloodstream infection are that children with PICC catheters should have laboratory etiological evidence in addition to fever and hypotension. Our data were extracted from children with acute leukemia, lymphoma, or anemia. Due to the lack of neutrophils, these children tend to suffer from infection of the mouth, anus week, respiratory tract. Some parents are reluctant to draw more blood samples on both sides for the culture, considering the piercing pain of children and funds of operation. We did not collect the exact etiology laboratory evidence. In the absence of adequate laboratory evidence, these cases are usually classified as suspected catheterrelated infections based on clinical indications. Thus, there is very limited evidence of catheter-related bloodstream infection in this cohort.

As for local infection, our criteria are local redness, swelling, heat, and pain at the puncture site. When only one of these symptoms may exist, the "local infection" will be recorded. However, these children may be simply stimulated by the dressing or disinfectant, or only have the effusion of the puncture site, which may also cause local redness. The culture of puncture site swabs usually has no evidence of etiology. Most children will get better 
or the symptoms disappear within 1-2 days. Due to the low resistance of children with blood diseases and the uncertainties of catheter-related infections, it is difficult for us to give objective evidence of infection based on this cohort. In future work, we will refine the relevant links of PICC-related infection complications for a more scientific and comprehensive assessment.

\section{Conclusions}

In summary, the Seldinger technology with B-ultrasound imaging is a recommended practice for the PICC placement of pediatric patients. The most common non-infectious complications of PICC catheter implantation in children with blood diseases were rash, followed by catheter occlusion, mechanical phlebitis, and catheter fracture. The catheter type is a key risk factor for catheter occlusion. To some extent, our nomograms are helpful for the prediction and prevention of PICC-associated phlebitis, rash occurrence, and catheter fracture complications for Chinese children with hematologic diseases.

\section{Acknowledgments}

Funding: The work of patient information inclusion and statistical analysis was supported by the special construction of vascular access for patients with blood diseases based on international cooperation (201920101402).

\section{Footnote}

Reporting Checklist: The authors have completed the MDAR checklist. Available at http://dx.doi.org/10.21037/apm-201771

Data Sharing Statement: Available at http://dx.doi. org/10.21037/apm-20-1771

Conflicts of Interest: All authors have completed the ICMJE uniform disclosure form (available at http://dx.doi. org/10.21037/apm-20-1771). The authors have no conflicts of interest to declare.

Ethical Statement: The authors are accountable for all aspects of the work in ensuring that questions related to the accuracy or integrity of any part of the work are appropriately investigated and resolved. The study was conducted in accordance with the Declaration of Helsinki (as revised in 2013). Our study has been were reviewed and approved by the clinical research ethics committee of Blood Diseases Hospital \& Institute of Hematology, Chinese Academy of Medical Sciences [HG2020007-EC-1]. Due to the low risk of retrospective project, consent was not required.

Open Access Statement: This is an Open Access article distributed in accordance with the Creative Commons Attribution-NonCommercial-NoDerivs 4.0 International License (CC BY-NC-ND 4.0), which permits the noncommercial replication and distribution of the article with the strict proviso that no changes or edits are made and the original work is properly cited (including links to both the formal publication through the relevant DOI and the license). See: https://creativecommons.org/licenses/by-nc-nd/4.0/.

\section{References}

1. Duwadi S, Zhao Q, Budal BS. Peripherally inserted central catheters in critically ill patients - complications and its prevention: A review. Int J Nurs Sci 2018;6:99-105.

2. Crawford M, Soukup SM, Woods SS, et al. Peripherally inserted central catheter program. Nurs Clin North Am 2000;35:349-60.

3. Simonetti G, Sommariva A, Lusignani M, et al. Prospective observational study on the complications and tolerability of a peripherally inserted central catheter (PICC) in neuro-oncological patients. Support Care Cancer 2020;28:2789-95.

4. Braswell LE. Peripherally inserted central catheter placement in infants and children. Tech Vasc Interv Radiol 2011;14:204-11.

5. Huasun Z. Nursing Science of Intravenous Infusion Therapy. Beijing: People's Military Medical Press, 2007.

6. Bourgeois FC, Lamagna P, Chiang VW. Peripherally inserted central catheters. Pediatr Emerg Care 2011;27:556-61; quiz 62-3.

7. Fadoo Z, Nisar MI, Iftikhar R, et al. Peripherally Inserted Central Venous Catheters in Pediatric Hematology/ Oncology Patients in Tertiary Care Setting: A Developing Country Experience. J Pediatr Hematol Oncol 2015;37:e421-3.

8. Velissaris D, Karamouzos V, Lagadinou M, et al. Peripheral Inserted Central Catheter Use and Related Infections in Clinical Practice: A Literature Update. J Clin Med Res 2019;11:237-46.

9. Xiang M, Li N, Yi L, et al. Causes and nursing 
countermeasures in pediatric PICC catheter complications. Pak J Pharm Sci 2016;29:335-7.

10. Society IN. Infusion Nursing Standards of Practice. J Infus Nurs 2006;29:S1-92.

11. Nichols I, Doellman D. Pediatric peripherally inserted central catheter placement: application of ultrasound technology. J Infus Nurs 2007;30:351-6.

12. Tan J, Liu L, Xie J, et al. Cost-effectiveness analysis of ultrasound-guided Seldinger peripherally inserted central catheters (PICC). Springerplus 2016;5:2051.

13. Wan G, Yan M. Puncture Point Hemostatic Effect Observation of Different Materials with Modified Seldinger Technique in PICC Catheter. Zhongguo Yi Liao Qi Xie Za Zhi 2015;39:388-90.

14. Scrivens N, Sabri E, Bredeson C, et al. Comparison of complication rates and incidences associated with different peripherally inserted central catheters (PICC) in patients with hematological malignancies: a retrospective cohort study. Leuk Lymphoma 2020;61:156-64.

15. Seckold T, Walker S, Dwyer T. A comparison of silicone and polyurethane PICC lines and postinsertion

Cite this article as: Chang LX, Chen YW, Wang MC, Zhao SY, Wang M, Tian Y, Tang L, Wang JX, Yang MM, Zhu XF, Zhang HM. Analysis of peripherally inserted central catheter-related complications: a retrospective cohort study of 2,974 children with blood diseases in a single center of China. Ann Palliat Med 2021;10(3):2971-2978. doi: 10.21037/apm-20-1771 complication rates: a systematic review. J Vasc Access 2015;16:167-77.

16. Walshe LJ, Malak SF, Eagan J, et al. Complication rates among cancer patients with peripherally inserted central catheters. J Clin Oncol 2002;20:3276-81.

17. Cheong K, Perry D, Karapetis C, et al. High rate of complications associated with peripherally inserted central venous catheters in patients with solid tumours. Intern Med J 2004;34:234-8.

18. Yap YS, Karapetis C, Lerose S, et al. Reducing the risk of peripherally inserted central catheter line complications in the oncology setting. Eur J Cancer Care (Engl) 2006;15:342-7.

19. Cardella JF, Cardella K, Bacci N, et al. Cumulative experience with 1,273 peripherally inserted central catheters at a single institution. J Vasc Interv Radiol 1996;7:5-13.

20. Abedin S, Kapoor G. Peripherally inserted central venous catheters are a good option for prolonged venous access in children with cancer. Pediatr Blood Cancer 2008;51:251-5. 


\section{Supplementary}

Table S1 Univariate logistic regression analysis for rash occurrence

\begin{tabular}{|c|c|c|c|c|c|}
\hline Factor & & Rash & Non-rash & Unadjusted OR $(95 \% \mathrm{Cl})$ & $P$ value \\
\hline Gender & female & 144 & 1013 & $0.678(0.546 \sim 0.837)$ & $<0.001$ \\
\hline \multirow[t]{3}{*}{ Age(year) } & $0-3$ & 162 & 636 & - & - \\
\hline & $4-6$ & 145 & 797 & $0.714(0.558 \sim 0.914)$ & 0.008 \\
\hline & $11-18$ & 55 & 403 & $0.536(0.382 \sim 0.741)$ & $<0.001$ \\
\hline \multirow[t]{2}{*}{ Insertion site } & above the elbow & 281 & 1179 & - & - \\
\hline & under the elbow & 172 & 1307 & $0.552(0.449 \sim 0.677)$ & $<0.001$ \\
\hline \multirow[t]{2}{*}{ Operation season } & spring & 129 & 559 & - & - \\
\hline & winter & 94 & 617 & $0.66(0.493 \sim 0.881)$ & 0.005 \\
\hline \multirow[t]{3}{*}{ Catheter type } & $3 F$ & 188 & 816 & - & - \\
\hline & $4 \mathrm{~F}$ & 151 & 1410 & $0.465(0.369 \sim 0.585)$ & $<0.001$ \\
\hline & power & 114 & 260 & 1.903 (1.449 2.494) & $<0.001$ \\
\hline
\end{tabular}

OR, odds ratio; $\mathrm{Cl}$, confidence interval; -, control group.

Table S2 Univariate logistic regression analysis for catheter occlusion.

\begin{tabular}{|c|c|c|c|c|c|}
\hline Factor & & Occlusion & Non-occlusion & Unadjusted OR (95\% Cl) & $P$ value \\
\hline Gender & female & 181 & 976 & $1.126(0.914 \sim 1.384)$ & 0.262 \\
\hline \multirow[t]{3}{*}{ Age(year) } & $0-3$ & 123 & 675 & - & - \\
\hline & $4-6$ & 116 & 826 & $0.771(0.586 \sim 1.013)$ & 0.062 \\
\hline & $11-18$ & 90 & 368 & $1.342(0.992 \sim 1.81)$ & 0.055 \\
\hline \multirow[t]{2}{*}{ Insertion site } & above the elbow & 296 & 1164 & - & - \\
\hline & under the elbow & 137 & 1342 & $0.401(0.322 \sim 0.498)$ & $<0.001$ \\
\hline \multirow[t]{2}{*}{ Operation season } & spring & 108 & 580 & - & - \\
\hline & winter & 100 & 611 & $0.879(0.654 \sim 1.18)$ & 0.391 \\
\hline \multirow[t]{3}{*}{ Catheter type } & $3 F$ & 152 & 852 & - & - \\
\hline & $4 \mathrm{~F}$ & 105 & 1456 & $0.404(0.31 \sim 0.525)$ & $<0.001$ \\
\hline & power & 176 & 198 & $4.982(3.821 \sim 6.513)$ & $<0.001$ \\
\hline
\end{tabular}

OR, odds ratio; $\mathrm{Cl}$, confidence interval; -, control group. 
Table S3 Univariate logistic regression analysis for phlebitis.

\begin{tabular}{|c|c|c|c|c|c|}
\hline Factor & & Phlebitis & Non-phlebitis & Unadjusted OR (95\% Cl) & $P$ value \\
\hline Gender & female & 107 & 1050 & $0.936(0.725 \sim 1.203)$ & 0.607 \\
\hline \multirow[t]{3}{*}{ Age(year) } & $0-3$ & 46 & 752 & - & - \\
\hline & $4-6$ & 87 & 855 & $1.663(1.154 \sim 2.426)$ & 0.007 \\
\hline & $11-18$ & 59 & 399 & 2.417 (1.617 3.636) & $<0.001$ \\
\hline \multirow[t]{2}{*}{ Insertion site } & above the elbow & 62 & 1398 & - & - \\
\hline & under the elbow & 220 & 1259 & $3.94(2.962 \sim 5.315)$ & $<0.001$ \\
\hline \multirow[t]{2}{*}{ Operation season } & spring & 65 & 623 & - & - \\
\hline & winter & 75 & 636 & $1.13(0.797 \sim 1.607)$ & 0.493 \\
\hline \multirow[t]{3}{*}{ Catheter type } & $3 F$ & 63 & 941 & - & - \\
\hline & $4 \mathrm{~F}$ & 209 & 1352 & 2.309 (1.732 3.119) & $<0.001$ \\
\hline & power & 10 & 364 & $0.41(0.196 \sim 0.772)$ & 0.01 \\
\hline
\end{tabular}

OR, odds ratio; $\mathrm{Cl}$, confidence interval; -, control group.

Table S4 Univariate logistic regression analysis for catheter fracture.

\begin{tabular}{|c|c|c|c|c|c|}
\hline Factor & & Catheter fracture & Non-catheter fracture & Unadjusted OR (95\% Cl) & $P$ value \\
\hline Gender & female & 68 & 1089 & $1.097(0.794 \sim 1.507)$ & 0.572 \\
\hline \multirow[t]{3}{*}{ Age(year) } & $0-3$ & 63 & 735 & - & - \\
\hline & $4-6$ & 55 & 887 & $0.723(0.496 \sim 1.052)$ & 0.09 \\
\hline & $11-18$ & 15 & 443 & $0.395(0.214 \sim 0.683)$ & 0.002 \\
\hline \multirow[t]{2}{*}{ Insertion site } & above the elbow & 38 & 1422 & - & - \\
\hline & under the elbow & 126 & 1353 & $3.485(2.431 \sim 5.11)$ & $<0.001$ \\
\hline \multirow[t]{2}{*}{ Operation season } & spring & 48 & 640 & - & - \\
\hline & winter & 32 & 679 & $0.628(0.393 \sim 0.991)$ & 0.048 \\
\hline \multirow[t]{3}{*}{ Catheter type } & $3 F$ & 87 & 917 & - & - \\
\hline & $4 \mathrm{~F}$ & 75 & 1486 & $0.532(0.386 \sim 0.732)$ & $<0.001$ \\
\hline & power & 2 & 372 & $0.057(0.009 \sim 0.18)$ & $<0.001$ \\
\hline
\end{tabular}

OR, odds ratio; $\mathrm{Cl}$, confidence interval; -, control group. 


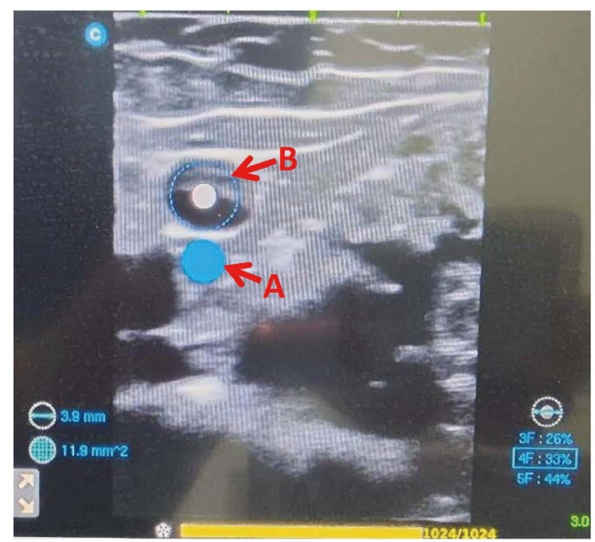

Figure S1 The ratio of catheter diameter to vessel diameter. (A) catheter diameter; (B) vessel diameter.

\begin{tabular}{|c|c|c|c|c|c|}
\hline & Factor & $P$ value & OR (95\% Cl) & & \multirow{9}{*}{ rash risk } \\
\hline Gender & $\square$ female: & $<0.001$ & $0.644(0.516-0.801)$ & 보 & \\
\hline \multirow{3}{*}{$\begin{array}{c}\text { Age } \\
\text { (year) }\end{array}$} & 口11-18: & $<0.001$ & $0.398(0.260-0.605)$ & F- & \\
\hline & प 4-6: & 0.015 & $0.696(0.519-0.930)$ & $F=-1$ & \\
\hline & प $7-10:$ & $<0.001$ & $0.454(0.313-0.656)$ & 벙 & \\
\hline \multirow{2}{*}{$\begin{array}{l}\text { Insertion } \\
\text { site }\end{array}$} & 口 under the elbo & v: 0.132 & $0.832(0.655-1.057)$ & 엥 & \\
\hline & 口winter: & 0.017 & $0.695(0.515-0.936)$ & $\mathrm{F}=\mathrm{I}$ & \\
\hline \multirow{2}{*}{$\begin{array}{l}\text { Operation } \\
\text { season }\end{array}$} & 口 autumn: & 0.029 & $0.723(0.540-0.966)$ & Fe-1 & \\
\hline & 口 summer: & 0.331 & $0.870(0.658-1.151)$ & $t=-1$ & \\
\hline \multirow{2}{*}{$\begin{array}{c}\text { Catheter } \\
\text { type }\end{array}$} & - $4 \mathrm{~F}:$ & 0.027 & $0.713(0.529-0.962)$ & $H=-1$ & \\
\hline & a power: & $<0.001$ & $3.018(2.082-4.383)$ & & $\Longrightarrow$ \\
\hline
\end{tabular}

Figure S2 Forest plot of multivariate logistic regression analysis for rash.

\begin{tabular}{|c|c|c|c|c|c|}
\hline \multicolumn{2}{|r|}{ Factor } & $P$ value & OR (95\% Cl) & i & \\
\hline Gender & 口 Female: & 0.508 & $1.078(0.862-1.348)$ & 田 & \\
\hline & 口 11-18: & 0.658 & $0.908(0.591-1.391)$ & $\mathrm{H}=-1$ & \\
\hline (year) & 口 4-6: & 0.049 & $0.721(0.059-0.997)$ & 国 & \\
\hline & 口7-10: & 0.059 & $0.680(0.454-1.014)$ & 酎 & \\
\hline Insertion site & $\boldsymbol{Q}$ under the elbow & v: 0.945 & $0.991(0.759-1.295)$ & 瀻 & risk \\
\hline & 口Winter: & 0.765 & $0.952(0.692-1.311)$ & 㟵 & \\
\hline season & 口Autumn: & 0.974 & $0.995(0.727-1.362)$ & $\mathrm{P}$ & \\
\hline & 口 Summer: & 0.537 & $1.102(0.811-1.499)$ & H-H & \\
\hline Catheter & 口 4F: & $<0.001$ & $0.475(0.337-0.667)$ & 回! & \\
\hline type & 口 Power: & $<0.001$ & $5.861(3.996-8.646)$ & 1 & $\longmapsto$ \\
\hline
\end{tabular}

Figure S3 Forest plot of multivariate logistic regression analysis for catheter occlusion. 


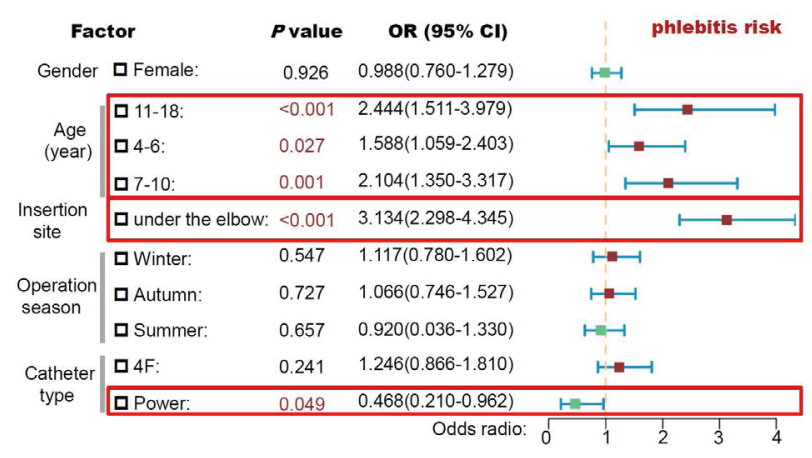

Figure S4 Forest plot of multivariate logistic regression analysis for phlebitis.

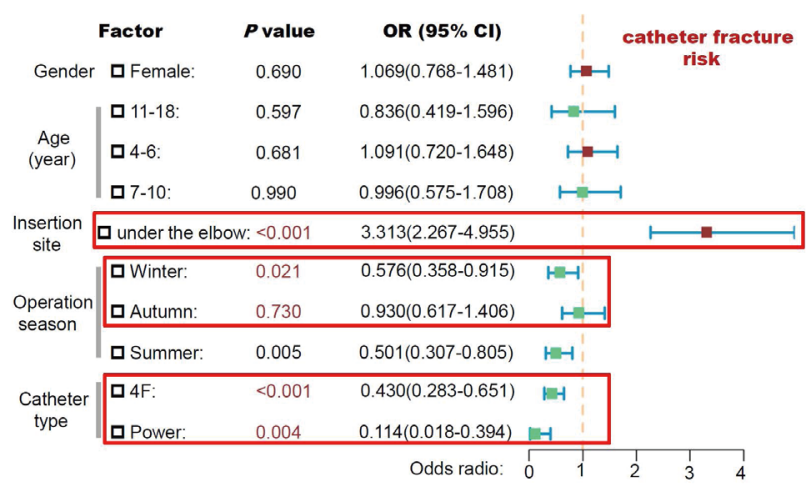

Figure S5 Forest plot of multivariate logistic regression analysis for catheter fracture.

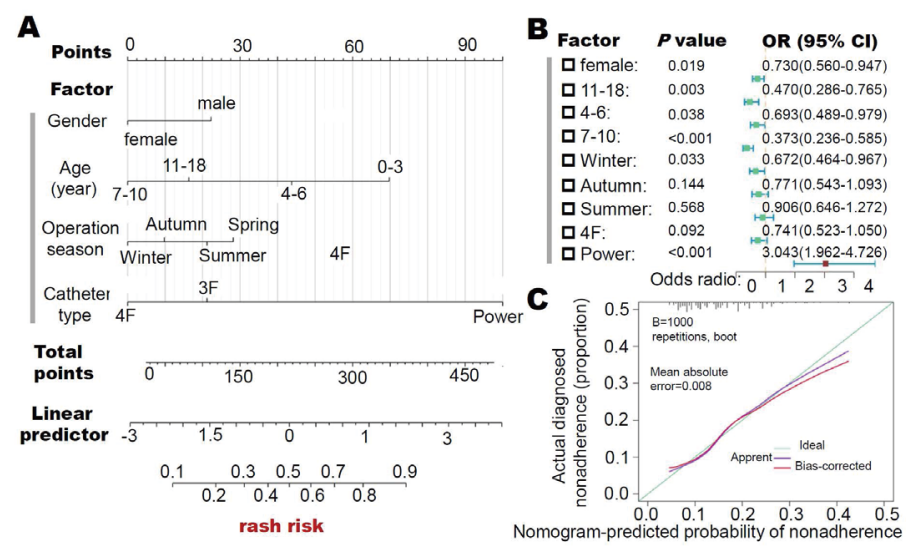

Figure S6 Modeling analysis based on the risk factors of rash. (A) Nomogram; (B) Forest plot; (C) Calibration curve. 

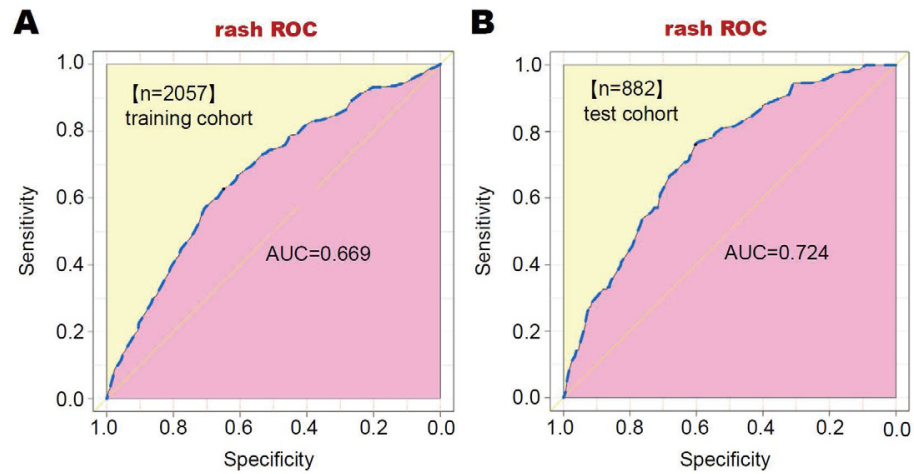

Figure S7 ROC data of rash. (A) training cohort. (B) test cohort.
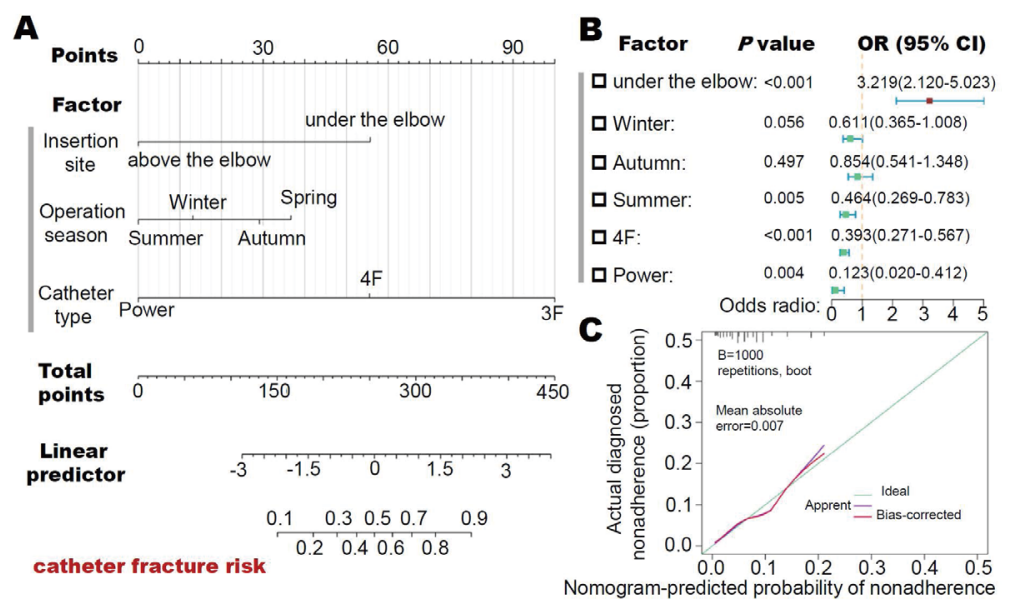

Figure S8 Modeling analysis based on the risk factors of catheter fracture. (A) Nomogram; (B) Forest plot; (C) Calibration curve.
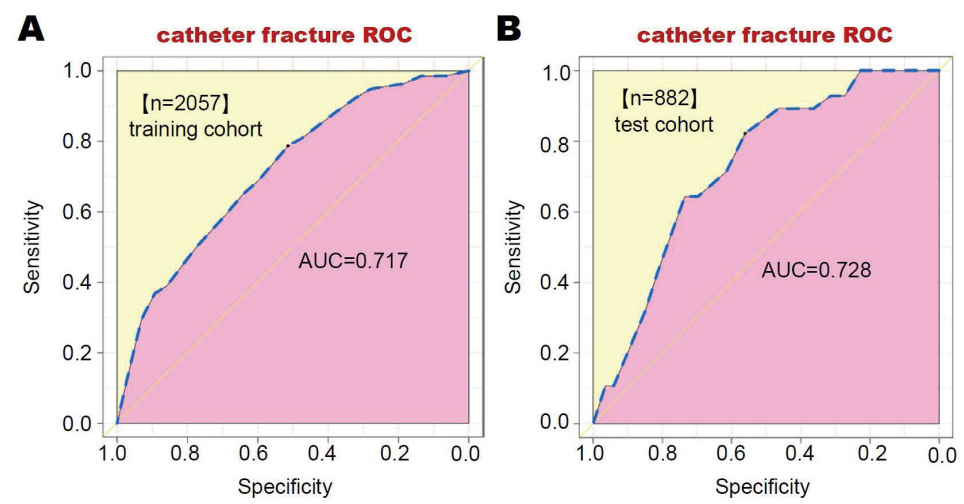

Figure S9 ROC data of catheter fracture. (A) training cohort; (B) test cohort. 